\title{
Improving the efficiency of farm management using modern digital technologies
}

\author{
Tatiana Grober $^{1, *}$, Oleg Grober ${ }^{1}$ \\ ${ }^{1}$ Don state technical University, 1, Gagarin square, 344000, Rostov-on-Don, Russia
}

\begin{abstract}
Around the world, farmers are increasingly turning to the concept of smart agriculture. The concept of smart agriculture includes the use of innovative digital technologies, mobile applications, sensors and tracking devices, communication channels, data analysis tools, and other intelligent solutions for users. This article discusses the farm of LLC "Rodon", located in the Rostov region. Due to its low profitability, the aim of the work was to improve the efficiency of farm management using modern trends in agricultural development and digital technologies. The activity of this farm can be represented as a model of multi-criteria optimization with target functions of profit from the sale of crops and increasing the yield of cultivated crops and restrictions on the ratio of areas by cultivated crops, by field areas, the number of purchased seeds, fertilizers, and other expenses. To optimize this model, the following tasks were solved: a plan for crop rotation of cultivated crops for 5 years was drawn up; a software package consisting of user applications "Profit calculation" and "Crop rotation" was developed. The user can quickly and easily determine their optimal strategy for the next year.
\end{abstract}

\section{Introduction}

The development of agriculture takes place with the use of new technologies throughout its history. The first gas tractors and industrial chemical fertilizers appeared in the 19th century, satellites were used for agriculture from the second half of the 20th century, the 21 st century is known for the use of drones equipped with cameras and sensitive sensors, inspecting fields, and the so-called Internet of things. Agricultural technologies are closely related to the development of information (digital) technologies. The population's food needs are increasing all the time, and traditional farming methods are not coping with them, so farmers are increasingly turning to the concept of smart agriculture.

For the development of agriculture, innovative technologies are used everywhere: in land management [1-3], increasing the yield of cultivated crops[4], in improving technical devices, and special hardware and software tools are being developed for integration into the farm management system [5,6].

Private farmers and organized farms would like to minimize costs and make optimal use of existing resources [7]. In addition, in addition to productivity, the main goal of smart agriculture is to increase its efficiency [8].

\footnotetext{
*Corresponding author: grober71@mail.ru
} 
The scientific literature uses various mathematical methods and approaches designed to optimize the functioning of farms [9].

Real-time decision-making tasks are considered in order to ensure profitability of agricultural activities and reduce the impact associated with limited water resources [5].

There is a general typological approach for analyzing crop rotation practices in a particular region based on administrative time series data [4]. Spatial data analysis methods are used [10]. But these approaches are justified in the case of long-term observations, a huge sample of data.

Many optimization models are formulated as mixed integer linear programming (MILP) problems [11].

The vast majority of research in this field is related to environmental issues [11-13].

However, to effectively achieve a specific goal, you need to be able to choose among a variety of modeling tools and optimization algorithms [5,14,15].

This article discusses the operation of a small farm with a low yield for eight years.

On the basis of data obtained during local surveys, it was found that land resources are used irrationally and the profit of this farm is insignificant.

The aim of the work was to improve the efficiency of farm management in accordance with current trends in agricultural development and using digital technologies.

Despite the lack of moisture, we can not consider the model of optimization of the activities of LLC "Rodon", as it was done in [5], they are too different. We don't have a large amount of data to use for time series analysis [4] or spatial data analysis [10].

The activity of this farm can be represented as a model of multi-criteria optimization with target functions of profit from the sale of crops and increasing the yield of cultivated crops and restrictions on the ratio of areas by cultivated crops, by field areas, the number of purchased seeds, fertilizers, and other expenses.

The uniqueness of this model lies in the fact that depending on the forecast of weather conditions for the coming year (dry, normal, rainy year), based on the prices of seeds (for each of the crops), the sale price of finished products, yield, gross harvest and the cost of growing crops, you can calculate the estimated profit. In addition, based on information about the market situation (growth in demand for wheat or sunflower), you can give preference (deviate from the standard) to one of the crops. A special scheme of crop rotation for 5 years is drawn up, allowing for the 5 th year to reach the indicators of the standard distribution of crops across fields.

In view of the fact that one of the target functions is to forecast possible profits, the user has the opportunity to determine their optimal strategy for the next year.

This problem is new.

This problem is relevant, since its solution leads to an increase in the yield of crops grown, and, consequently, to an increase in the profit of the farm.

\section{Materials and methods}

The Rodon farm LLC is located in the Priazovskaya soil and climate zone of the Rostov region, in the Rodionovo-Nesvetaysky district. The main and only activity is crop production: growing wheat, sunflower and barley. The leading crop is wheat.

The table shows data on the yield, gross harvest and areas of the crops under consideration for this farm in the period from 2012 to 2019. 
Table 1. Source data.

\begin{tabular}{|c|c|c|c|c|c|c|c|c|c|}
\hline \multicolumn{10}{|c|}{ Data On The Yield In Hundredweight } \\
\hline $\begin{array}{c}\text { Yea } \\
\mathbf{r}\end{array}$ & $\begin{array}{c}\text { Wh. } \\
\text { thea } \\
\mathbf{t}\end{array}$ & $\begin{array}{c}\text { Whea } \\
\mathbf{t} \\
\text { Gross } \\
\text { Yield }\end{array}$ & $\begin{array}{c}\text { Whea } \\
\text { t. } \\
\text { Yield }\end{array}$ & $\begin{array}{c}\text { Ha. } \\
\text { Barle } \\
\mathbf{y}\end{array}$ & $\begin{array}{c}\text { Barle } \\
\text { ygross } \\
\text { Yield }\end{array}$ & $\begin{array}{c}\text { Barley. } \\
\text { Yield }\end{array}$ & $\begin{array}{c}\text { Ha. } \\
\text { Sunfl } \\
\text { ower }\end{array}$ & $\begin{array}{c}\text { Sunflo } \\
\text { wer } \\
\text { Gross } \\
\text { Yield }\end{array}$ & $\begin{array}{c}\text { Sunfl } \\
\text { ower } \\
\text { Yield }\end{array}$ \\
\hline 2012 & 150 & 6109 & 40.73 & 40 & 1036 & 25.9 & 140 & 2139 & 15.28 \\
\hline 2013 & 140 & 4035 & 28.82 & 70 & 884 & 12.63 & 140 & 3459 & 24.7 \\
\hline 2014 & 105 & 5880 & 56 & 100 & 1507 & 15.07 & 137 & 3622 & 26.44 \\
\hline 2015 & 138 & 4563 & 33.06 & 135 & 1933 & 14.32 & 70 & 1386 & 19.8 \\
\hline 2016 & 142 & 6334 & 44.6 & 138 & 3187 & 23.09 & 70 & 1437 & 20.53 \\
\hline 2017 & 145 & 7565 & 42.17 & 145 & 2777 & 19.15 & 70 & 908 & 12.97 \\
\hline 2018 & 150 & 5029 & 33.53 & 100 & 3098 & 30.98 & 33 & 11 & 744 \\
\hline 2019 & 145 & 3654 & 45 & 112 & 3652 & 33 & 70 & 3190 & 28.57 \\
\hline
\end{tabular}

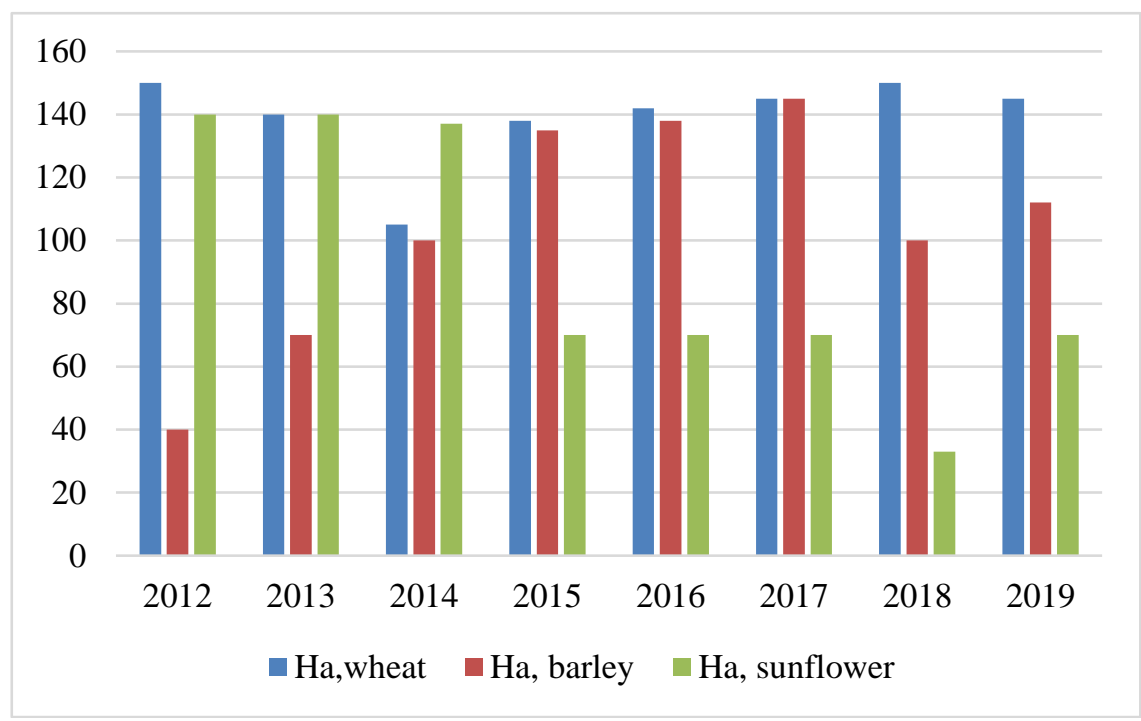

Fig. 1. Distribution of arable land by cultivated crops.

Shown in fig. 1 the diagram clearly shows the distribution of arable land by cultivated crops.

To increase the efficiency of farm management, the following projects should be implemented:

1) to increase the yield of cultivated crops, such as wheat, barley and sunflower, it is necessary to draw up a scientifically based crop rotation system, as well as a crop rotation plan for 5 years;

2) develop a software package in the object-oriented programming language VBA, consisting of the following software products:

- user application "Profit calculation", which allows you to calculate the profit based on the prices of seeds (for each crop), the sale price of finished products, yield and gross harvest, the cost of growing crops, as well as weather conditions;

- automate filling of the database "Data on the yield in hundredweight»;

- custom application "Crop rotation" to bring to the form of a recommendation on placement of crops in farm fields given the rotation, taking into account the situation on the grain market at a particular point in time, and visualize the data in graphs.

Based on the information provided by the program, the user can quickly and easily 
determine their optimal strategy for the next year.

\section{Results}

After analyzing the available information [16], we will form a plan for 5 years of crop rotation for the farm under consideration (tab. 2). Here, under the words wheat 1 and wheat 2 , we mean placing wheat for the 1 st year and the 2 nd year in a row on the same field.

Table 2. Crop rotation plan (balance).

\begin{tabular}{|c|c|c|c|c|c|}
\hline \multicolumn{7}{|c|}{ Crop rotation plan (balance) } \\
\hline $\begin{array}{c}\text { The } \\
\text { number } \\
\text { of the } \\
\text { field }\end{array}$ & 1st year & 2nd year & 3rd year & 4th year & 5th year \\
\hline 1 & steam & wheat 1 & wheat 2 & barley & steam \\
\hline 2 & wheat 1 & wheat 2 & barley & steam & wheat 1 \\
\hline 3 & wheat 2 & barley & sunflower & steam & wheat 1 \\
\hline 4 & barley & sunflower & steam & wheat 1 & wheat 2 \\
\hline 5 & sunflower & steam & wheat 1 & wheat 2 & barley \\
\hline 6 & wheat 1 & wheat 2 & steam & wheat 1 & wheat 2 \\
\hline 7 & wheat 2 & steam & wheat 1 & wheat 2 & sunflower \\
\hline 8 & steam & wheat 1 & wheat 2 & sunflower & steam \\
\hline
\end{tabular}

If the price of wheat due to some conditions increases for 2 years (although it is usually quite stable), then it makes sense to use more fields for growing wheat to increase the profit of the farm (table.3).

Table 3. Crop rotation plan (predominance of wheat).

\begin{tabular}{|c|c|c|c|c|c|}
\hline \multicolumn{5}{|c|}{ Crop rotation plan (predominance of wheat). } \\
\hline $\begin{array}{c}\text { The } \\
\text { number } \\
\text { of the } \\
\text { field }\end{array}$ & 1st year & 2nd year & 3rd year & 4th year & 5th year \\
\hline 1 & steam & wheat 1 & wheat 2 & barley & steam \\
\hline 2 & wheat 1 & wheat 2 & wheat 2 & steam & wheat 1 \\
\hline 3 & wheat 2 & barley & steam & wheat 1 & wheat 2 \\
\hline 4 & barley & sunflower & steam & wheat 1 & wheat 2 \\
\hline 5 & sunflower & steam & wheat 1 & wheat 2 & barley \\
\hline 6 & wheat 1 & wheat 2 & wheat 2 & steam & wheat 1 \\
\hline 7 & wheat 2 & steam & wheat 1 & wheat 2 & sunflower \\
\hline 8 & steam & wheat 1 & wheat 2 & sunflower & steam \\
\hline
\end{tabular}

If two years in a row will increase the price of sunflower, it is worth taking the risk and allocate a large area for it (table.4). 
Table 4. Crop rotation plan (increasing the area of sunflower).

\begin{tabular}{|c|c|c|c|c|c|}
\hline \multicolumn{6}{|c|}{ Crop rotation plan (increasing the area of sunflower). } \\
\hline $\begin{array}{c}\text { The } \\
\text { number } \\
\text { of the } \\
\text { field }\end{array}$ & 1st year & 2nd year & 3rd year & 4th year & 5th year \\
\hline 1 & steam & wheat 1 & wheat 2 & barley & steam \\
\hline 2 & wheat 1 & wheat 2 & sunflower & steam & wheat 1 \\
\hline 3 & wheat 2 & barley & sunflower & steam & wheat 1 \\
\hline 4 & barley & sunflower & steam & wheat 1 & wheat 2 \\
\hline 5 & sunflower & steam & wheat 1 & wheat 2 & barley \\
\hline 6 & wheat 1 & wheat 2 & sunflower & steam & wheat 1 \\
\hline 7 & wheat 2 & steam & wheat 1 & wheat 2 & sunflower \\
\hline 8 & steam & wheat 1 & wheat 2 & sunflower & steam \\
\hline
\end{tabular}

It should be taken into account that the next year will be low-profit due to soil depletion.

If there is a misalignment for one year, then, as a rule, after a year it is possible to compensate for it with the help of crop rotation.

In tab. 3 and 4 experimental were 3 years with the subsequent exit from the extreme state. And, thanks to the use of a scientific approach, the situation is leveled within 2 years. That is, in the 5th year of crop rotation, the distribution of crops across fields is identical to the balanced one (tab. 2). The results suggest that such experiments are possible.

We note that, according to the proposed crop rotation plan, the average ratio of areas for cultivated crops is maintained (tab. 5).

Table 5. Distribution of crops by field area.

\begin{tabular}{|c|c|c|c|c|c|}
\hline Culture & Steam & Wheat 1 & Wheat 2 & Barley & Sunflower \\
\hline $\begin{array}{c}\text { Area, ha } \\
\text { 1st year }\end{array}$ & 105 & 175 & 105 & 40 & 60 \\
\hline 2nd year & 105 & 105 & 175 & 60 & 40 \\
\hline 3rd year & 138 & 105 & 105 & 77 & 60 \\
\hline 4th year & 137 & 138 & 105 & 35 & 70 \\
\hline 5th year & 105 & 137 & 138 & 60 & 45 \\
\hline
\end{tabular}

And, although, in the 2nd and 3rd year there is some decline (in areas of wheat), but in the 4th and 5th year everything is normal again.

Fig. 2 shows a diagram of the distribution of crops by field area, and fig. 3 - by year of crop rotation.

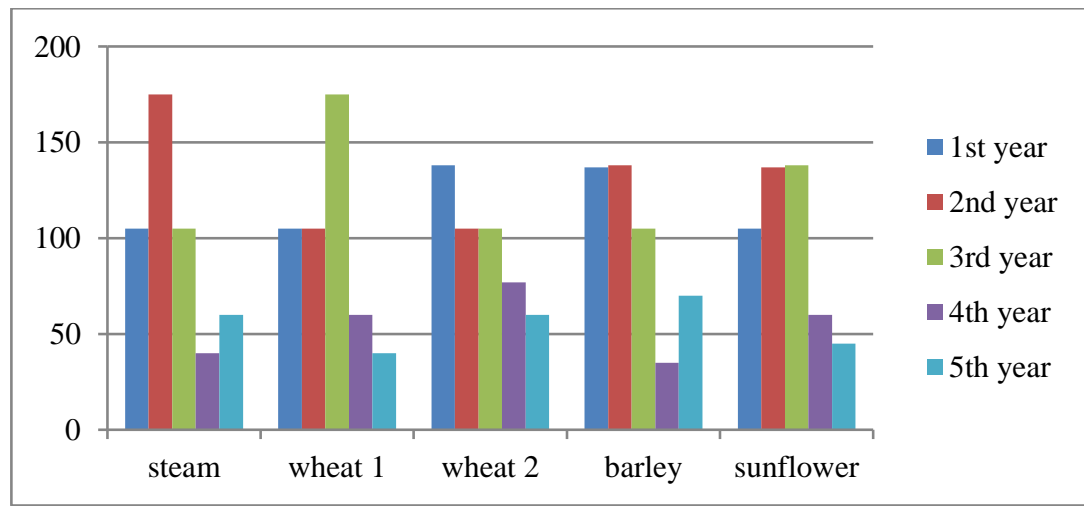

Fig. 2. Distribution of crops by field area. 


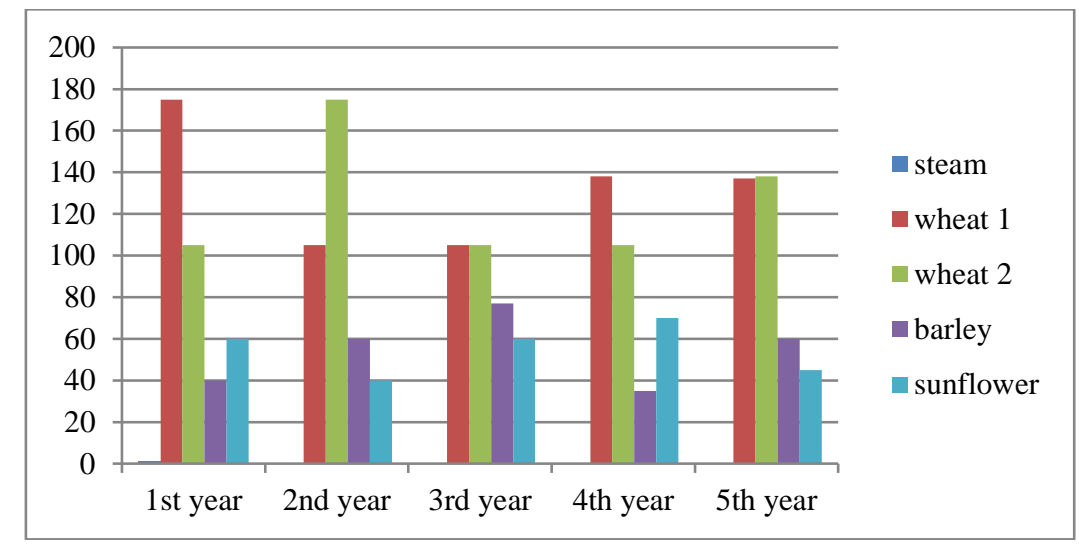

Fig. 3. The location of crops from year to year crop rotation.

Now we are writing the creation and use of the software package.

First of all, consider the user application "Calculating profits". The activity of this farm can be represented as a model of multi criteria optimization (1)-(3).

$$
\begin{gathered}
z_{1}(x)=\sum_{j=1}^{3} P_{j}(x) \cdot V_{j}(x)-\left(\sum_{j=1}^{3} s m_{j}(x) \cdot g+d(x)+c(x)\right) \rightarrow \max \\
z_{2}(x)=\sum_{j=1}^{3} u_{j}(x) \rightarrow \max
\end{gathered}
$$

Here, $\mathrm{z}_{1}$ and $\mathrm{z}_{2}$ - are the target functions of farm profit and increasing crop yields, $P_{j}(x)$ - price of 1 ton of $j$-th crop, $V_{j}(x)$ - the gross yield of the $j$-th culture, $s m_{j}(x)$ - expenses for purchasing $j$-th crop seeds, $g$ - multiplier responsible for weather conditions $(g \in$ $\{0,8$ - rainy year, 1 - normal year, $1,2-$ dry year $\}), u_{j}(x)$ - yield of the $j$-th crop, (j€\{wheat, barley, sunflower $\})$.

A system of restrictions on available resources, as well as other expenses.

$$
\left\{\begin{array}{c}
\sum_{i=1}^{k} S_{i}(w(x)) \geq 270 \\
\sum_{i=1}^{k} S_{i}(b(x)) \geq 50 \\
\sum_{i=1}^{k} S_{i}(s(x)) \geq 60 \\
\sum_{i=1}^{k} S_{i}(f(x)) \geq 100 \\
\sum_{i=1}^{8} S_{i}(x) \leq 485 \\
\sum_{j=1}^{3} s m_{j}(x) \geq 0 \\
d(x) \geq 0 \\
c(x) \geq 0
\end{array}\right.
$$

$S_{i}(w(x))$ - area of the $i$-th field occupied by wheat, $S_{i}(b(x))$ - the area of the $i$-th field occupied by barley, $S_{i}(s(x))$ - area of the $i$-th field occupied by sunflower, $S_{i}(f(x))$ - the area of the $i$-th field left under par, $k$-the number of fields $(k=\overline{1,8}), d(x)$ - costs for the purchase of fertilizer, $c(x)$ - other expenses (other expenses include expenses for salary of workers, use of agricultural machinery, fuel, etc.).

Let's look at the functioning of the user application "Profit calculation". When the application is launched, the Profit calculation form window opens (fig. 4). 
Using this form, it is possible to calculate the profit based on the prices of seeds (for each crop), the sales price of the finished product, the yield and gross harvest, and the cost of growing crops.

Selecting the switch in the Weather conditions list is not accidental, since the time of application and the amount of fertilizer depends on the weather forecast for the next year. It is known that for growing wheat on depleted soil, the correction factor for calculating the amount of fertilizers is 1.2 [4]. Then, when calculating the profit, the amount of fertilizer will be multiplied by 1.2. For rainy and normal (average) years, the correction coefficients are 0.8 and 1.0 , respectively.

After entering other expenses and clicking OK, the corresponding value will appear in the Profit field on the forum (fig.4).

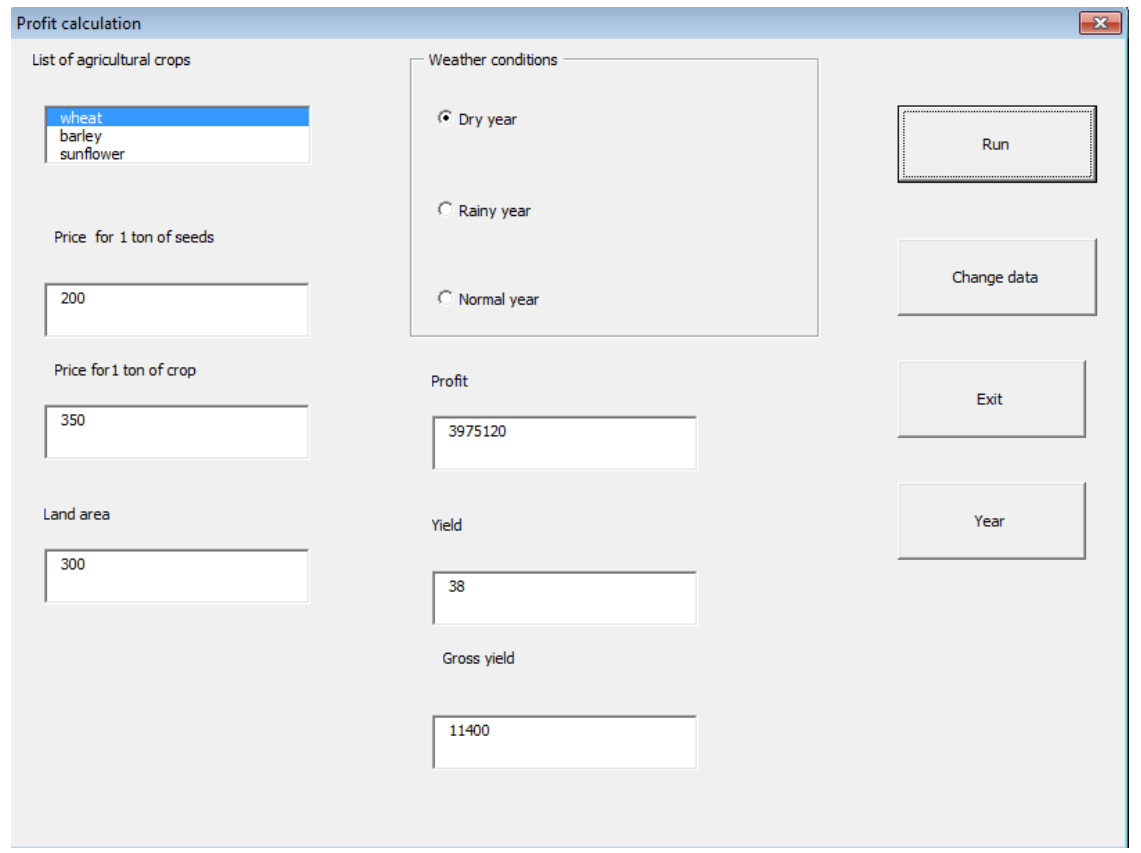

Fig. 4. The result of the calculation of profit.

Repeating the above algorithm for barley and sunflower crops from the List of crops, you can calculate the possible profit from growing these plants.

Consider filling in the database "Data on the yield in hundredweight".

The developed application allows you to forecast the profit for each crop for a specific year. Therefore, to successfully fill in the database "Data on the yield in hundredweight", first click the Year button. After entering the data, click OK (fig. 5). 


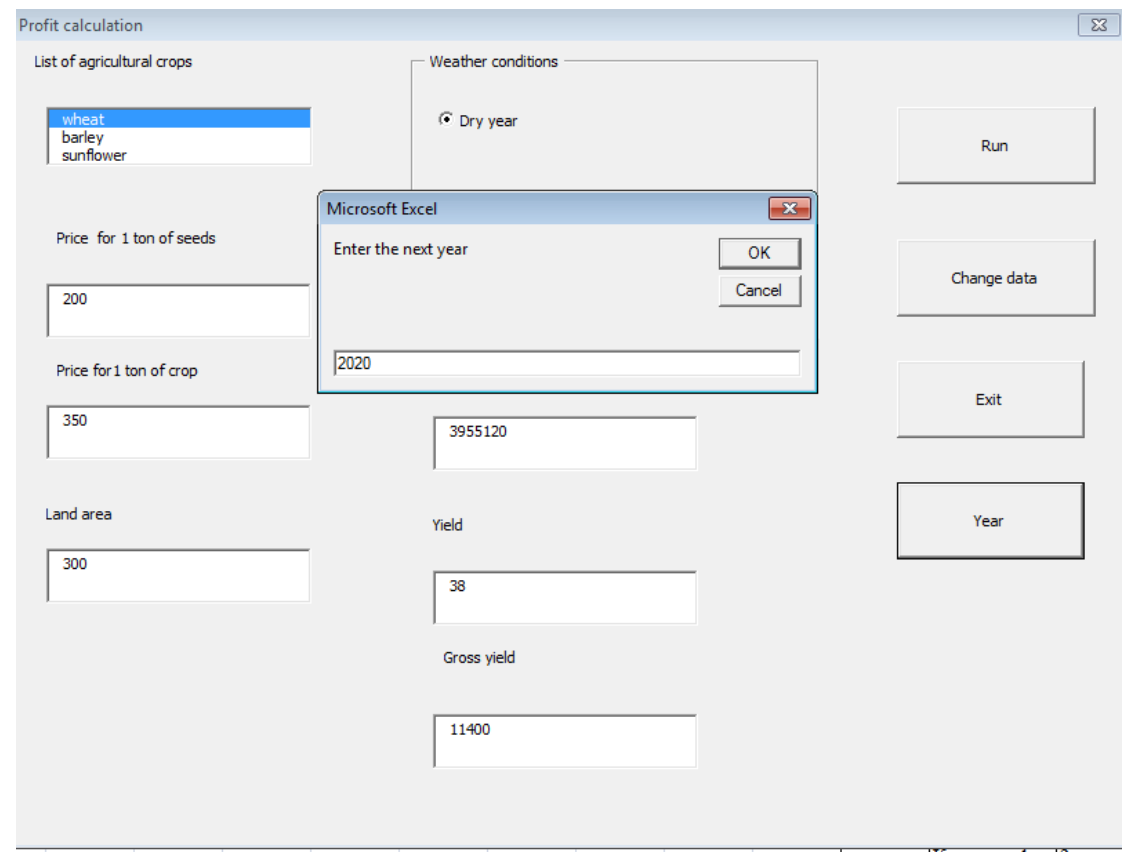

Fig. 5. Filling database using the form.

Information about the year is immediately entered in the database on an Excel sheet. Next, we perform the algorithm described above, and the data entered from the form fields is automatically entered into the database.

Since the task of the application is to forecast possible profits based on the available initial data and current trends in the economy, the user can quickly and easily determine their strategy for the next year.

Consider operation of the user application "Crop rotation". Launch the Crop rotation form window (fig. 6).

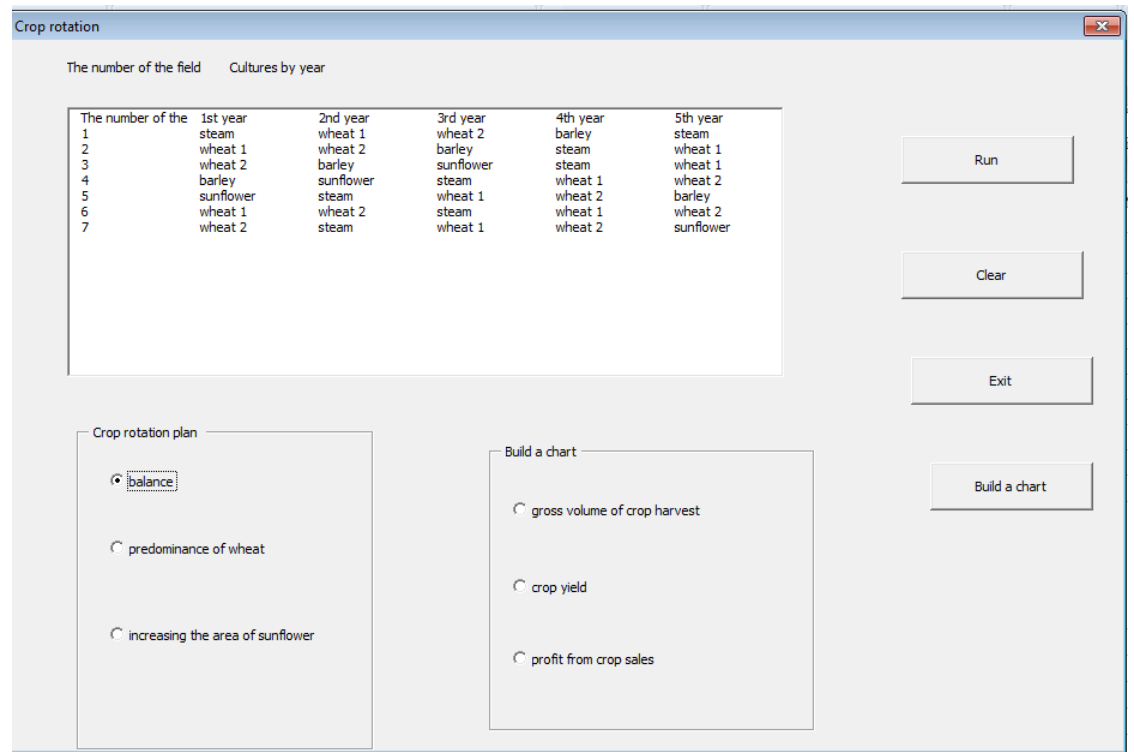

Fig. 6. User form "Crop rotation". 
In the central part of the form window, there is a list control whose elements are the field numbers of the farm under consideration and the types of plants grown in the specified fields for each of the 5 years of crop rotation.

To see one of the three suggested crop rotation plans, make one of the switches in the Crop rotation plan group active and click the Run button. The corresponding plan will be displayed in the list control field.

In order to build one of the diagrams of the second group of switches, you must make one of the corresponding switches active (fig.7) and click the Build a chart button.

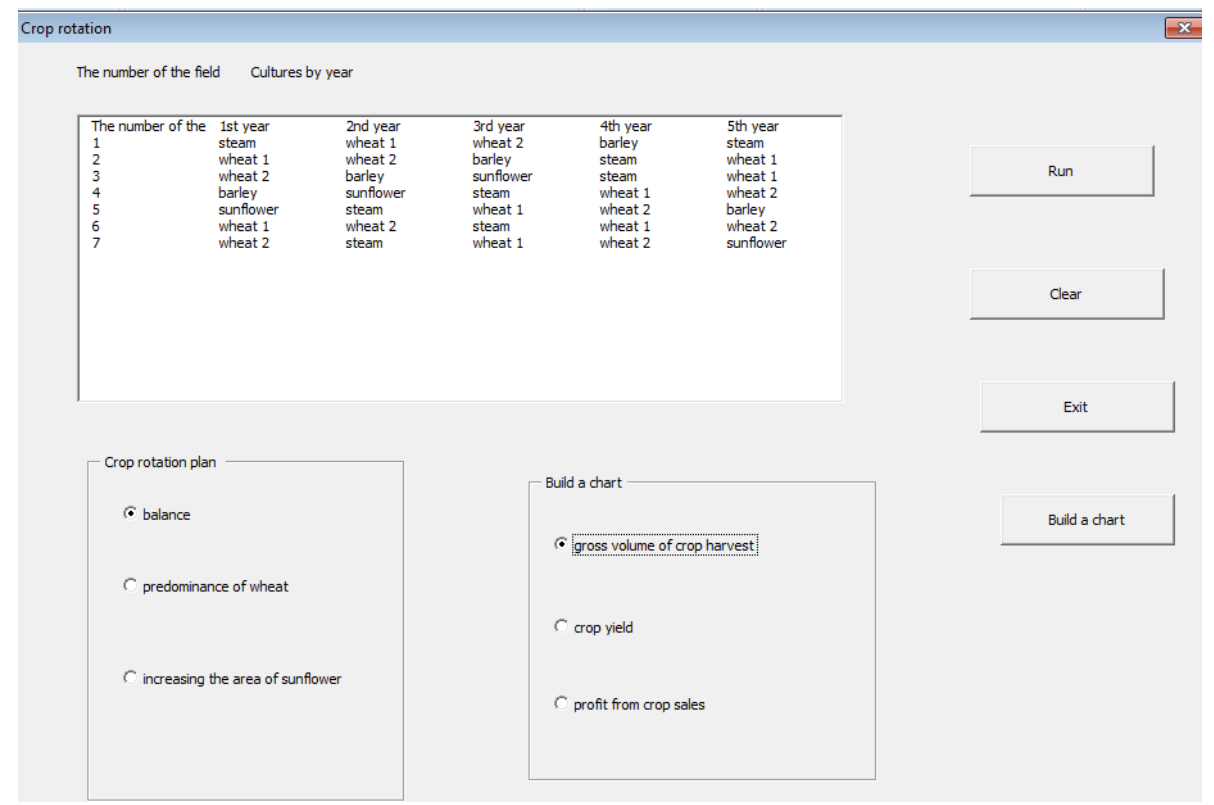

Fig. 7. Activating the switch in the plotting group.

The result of the construction can be seen on the active Excel sheet (Fig. 8).

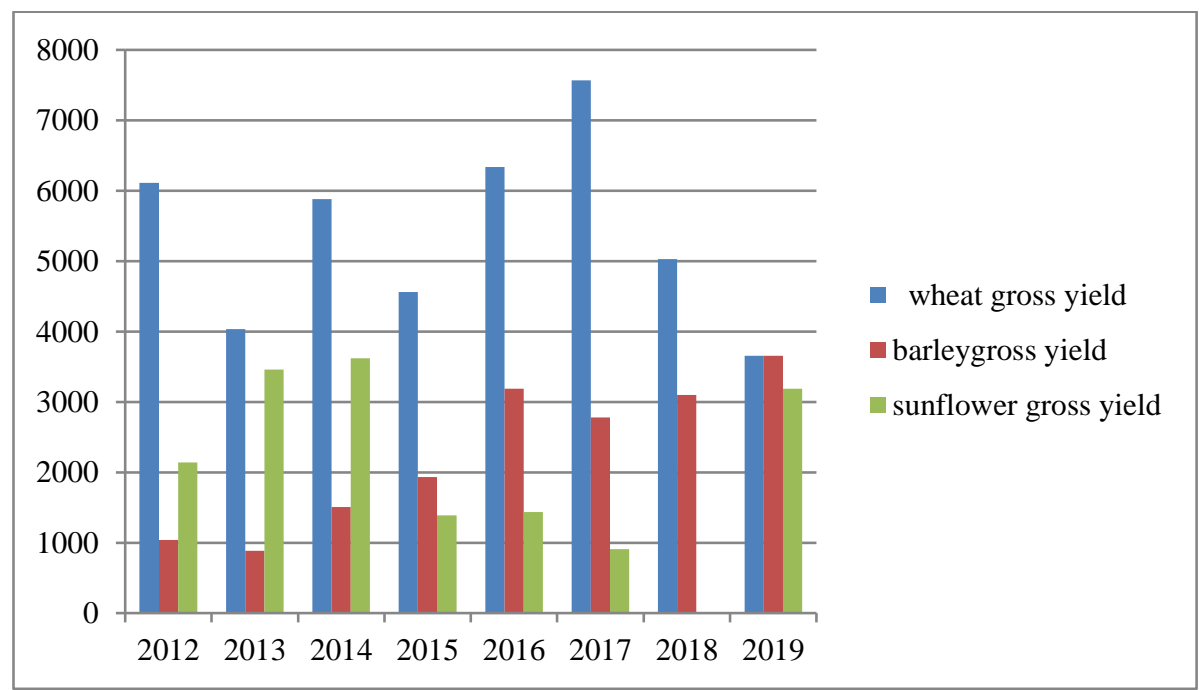

Fig. 8. The chart on gross yield of crops.

Since many of the model parameters are variables, it is difficult to find an exact solution 
to the problem. To study this model, we used numerical Monte - Carlo methods.

About 100 numerical experiments were performed and, with a discrepancy of about 0.0001 , the results obtained are consistent with the data obtained empirically.

This allows us to conclude that the forecast of possible profit (determined by the program) is sufficiently reliable.

\section{Conclusions}

This paper reflects the concept of smart agriculture. Depending on the climatic conditions, soil composition and cultivated crops, a crop rotation plan is drawn up for 5 years. A software package has been developed that allows you to manage this process, as well as calculate the estimated profit of the farm depending on weather forecasts for the coming year.

The use of modern digital technologies can significantly simplify the decision making process and make farm management the most effective.

\section{References}

1. D.C. Nielsen, M.F. Vigil, J.G. Benjamin, Field Crops Research 120(231), 254-261 (2011)

2. D. Cong Hiep Nguyen, J.C. Ascough, H.R. Maier, G.C. Dandy, A.A., Environmental Modelling \& Software 97, 32-45 (2017)

3. W. Verhagen, E.H. van der Zanden, M. Strauch, A.J.A. van Teeffelen, P.H. Verburg, Environmental Science \& Policy 84, 186-196 (2018)

4. S. Stein, H.-H. Steinmann, European Journal of Agronomy 92, 30-40 (2018)

5. K.R. Fowler, E.W. Jenkins, C. Ostrove, J.C. Chrispell, M. Parno, Environmental Modelling \& Software 69, 280-291 (2015)

6. C. Peter, K. Helming, C. Nendel, Renewable and Sustainable Energy Reviews 67, 461476 (2017)

7. J.C.J. Groot, G.J.M. Oomen, W.A.H. Rossing, Agricultural Systems 110, 63-77 (2012)

8. M. Marshall, K. Tu, J. Brown, Remote Sensing of Environment 217, 258-271 (2018)

9. Chongfeng Ren, Zhehao Li, Hongbo Zhang, Journal of Cleaner Production 21010, 1224 (2019)

10. G.W. Mueller-Warrant, K.M. Trippe, G.W. Whittaker, N.P. Anderson, C.S. Sullivan, International Journal of Applied Earth Observation and Geoinformation 60, 22-37 (2017)

11. F. Capitanescu, A. Marvuglia, T. Navarrete Gutiérrez, E. Benetto, Journal of Cleaner Production 14720, 197-205 (2017)

12. C. Mosnier, A. Duclos, J. Agabriel, A. Gac, Agricultural Systems 157, 202-215 (2017)

13. E.I. Teixeira, J. de Ruiter, A.-G. Ausseil, A. Daigneault, F. Ewert, Science of The Total Environment 616-617, 785-795 (2018)

14. K. Srivastava, A. Jain Bhutoria, J.K. Sharma, A. Sinha, P. Chandra Pandey, Society and Environment 16, 100258 (2019)

15. C. Buontempo, R. Hutjes, P. Beavis, J. Berckmans, D. Dee, Weather and Climate Extremes 17, 100226 (2019) doi: 10.1016/j.wace.2019.100226

16. N. Sukhomlinova, International research journal 11(77), 58-61 (2018) doi:10.23670/IRJ.2019.89.11.047 